Article

\title{
Low Temperature Synthesis of Phase Pure MoAlB Powder in Molten $\mathrm{NaCl}$
}

\author{
Cheng Liu ${ }^{1}{ }^{(}$, Zhaoping Hou ${ }^{2}{ }^{\oplus}$, Quanli Jia ${ }^{3}{ }^{\oplus}$, Xueyin Liu ${ }^{4, *}$ and Shaowei Zhang ${ }^{1, *}$ \\ 1 College of Engineering, Mathematics and Physical Sciences, University of Exeter, Exeter EX4 4QF, UK; \\ foxbat25mig@163.com \\ 2 College of Materials Science and Engineering, Taiyuan University of Technology, Taiyuan 030024, China; \\ houzhaoping@tyut.edu.cn \\ 3 Henan Key Laboratory of High Temperature Functional Ceramics, Zhengzhou University, \\ Zhengzhou 450052, China; jiaquanli@zzu.edu.cn \\ 4 College of Civil Engineering and Architecture, Quzhou University, Quzhou 32400, Zhejiang, China \\ * Correspondence: kklldliu@163.com (X.L.); s.zhang@exeter.ac.uk (S.Z.)
}

Received: 2 December 2019; Accepted: 6 February 2020; Published: 9 February 2020

\begin{abstract}
MoAlB fine powders were prepared in molten $\mathrm{NaCl}$ from $\mathrm{Al}, \mathrm{B}$ and Mo powders. The effects of key parameters affecting the synthesis process and phase morphology were examined and the underpinning mechanisms proposed. MoAlB product particles exhibited different shapes/sizes, as follows: spherical grains $(1 \sim 3 \mu \mathrm{m})$, plate-like particles $(<5 \mu \mathrm{m}$ in diameter) and columnar crystals with lengths up to $20 \mu \mathrm{m}$ and diameters up to $5 \mu \mathrm{m}$, resultant from different reaction processes. Phase pure MoAlB was synthesised under the following optimal conditions: use of $140 \%$ excess $\mathrm{Al}$ and $6 \mathrm{~h}$ of firing at $1000{ }^{\circ} \mathrm{C}$. This temperature was at least $100{ }^{\circ} \mathrm{C}$ lower than required by other methods/techniques previously reported. At the synthesis condition, Mo first reacted with $\mathrm{Al}$ and $\mathrm{B}$, forming $\mathrm{Al}_{8} \mathrm{Mo}_{3}$ and $\mathrm{MoB}$, respectively, which further reacted with excess $\mathrm{Al}$ to form $\mathrm{Al}$-rich $\mathrm{Al}-\mathrm{Mo}$ phases and MoAlB. The Al-rich Al-Mo phases further reacted with the residual B, forming additional MoAlB. The molten $\mathrm{NaCl}$ played an important role in accelerating the overall synthesis process.
\end{abstract}

Keywords: MoAlB; molten salt synthesis; low temperature; $\mathrm{NaCl}$; boron

\section{Introduction}

Ternary transition metal borides have layered structures similar to MAX phase materials [1] and are also regarded as a new class of promising non-oxide ceramics. Among them, MoAlB has attracted particular attention because of its many excellent properties and great application potential (e.g., electrocatalysis, composite reinforcement, solid lubrication and high temperature coating). It has a good electrical/thermal conductivity, small thermal expansion, great compressive strength and high fractural toughness [2-7]. It also has been confirmed to be stable at up to $1400{ }^{\circ} \mathrm{C}$ in an inert atmosphere [3]. Differently from in $\mathrm{MoB}$, the $\mathrm{Al}$ atoms in MoAlB are "sandwiched" between the MoB layers, which renders MoAlB very oxidation resistant (via the formation of a dense alumina layer from the initial oxidation on heating) $[2,3,8,9]$.

Bulk or powder-formed MoAlB can be synthesised by using various techniques/methodologies, including the Al flux method, spark plasma sintering (SPS), hot pressing and conventional mixed powder technique. The $\mathrm{Al}$ flux method [1,10-12] requires a very high operation temperature (between 1400 and $\left.1800^{\circ} \mathrm{C}\right)$, and is mainly used to synthesise MoAlB single crystals (>100 $\left.\mu \mathrm{m}\right)$. SPS [13] and hot pressing $[3,8,9]$ require a lowered firing temperature $\left(1100 \sim 1200{ }^{\circ} \mathrm{C}\right)$ but a high pressure. They are mainly used to prepare bulk MoAlB from $\mathrm{MoB}$ and $\mathrm{Al}$ powders. To our knowledge, the only method that has been attempted to date to synthesise MoAlB powder is the conventional mixed powder 
technique [6,14], i.e., directly heating a mixture of $\mathrm{MoB}$ and $\mathrm{Al}$ at a high temperature $\left(>1100{ }^{\circ} \mathrm{C}\right)$. Unfortunately, with this technique, it is difficult to prepare high quality (phase pure, good dispersion and fine size) MoAlB powders, because some intermediate/impurity phases (e.g., MoB $_{2}$ ) almost always remain in the final product powder.

In the work reported here, a liquid salt assisted synthesis method was used to prepare MoAlB fine powder from Mo, Al and B powders. The main factors affecting the synthesis process and product's microstructure/morphology were examined and the underpinning mechanisms discussed.

\section{Experimental Procedure}

\subsection{Raw Materials and Sample Preparation}

$\mathrm{Al}$ (purity 99.7\%, overall size $<25 \mu \mathrm{m}$ ), amorphous B (purity 95\%), and Mo (purity $\geq 99 \%$, overall size $<250 \mathrm{~nm})$ powders from Sigma-Aldrich were utilized as the starting materials, and $\mathrm{NaCl}(\geq 99 \%)$ was used to form a liquid medium. The three raw materials were mixed in the stoichiometric ratios corresponding to Reaction 1 (i.e., $0.96 \mathrm{~g} \mathrm{Mo}, 0.108 \mathrm{~g} \mathrm{~B}$ and $0.27 \mathrm{~g} \mathrm{Al}$ ), or non-stoichiometric ratios with excess $\mathrm{Al}$, followed by further combination with $20 \mathrm{~g} \mathrm{NaCl}$ in an agate mortar. The powder mix was contained in a covered graphite crucible, placed in a tube furnace and then heated in argon at $5{ }^{\circ} \mathrm{C} / \mathrm{min}$ to a given temperature within $850-1200{ }^{\circ} \mathrm{C}$. After $6 \mathrm{~h}$ at the temperature, the sample was furnace-cooled to room temperature.

$$
\mathrm{Mo}+\mathrm{Al}+\mathrm{B}=\mathrm{MoAlB}
$$

The residual salt in the fired samples was removed by repeated water-washing. For some samples, a $6 \mathrm{M} \mathrm{HCl}$ solution was further used to leach out the residual $\mathrm{Al}$, followed by rinsing with distilled water. All of the resultant samples, after oven-drying overnight at $100{ }^{\circ} \mathrm{C}$, were subjected to detailed characterisation.

\subsection{Sample Characterisation}

The phases in the fired/purified samples were identified based on X-ray diffraction (XRD) analysis. The diffractometer (Brukers D8 advance reflection diffractometer, Karlsruhe, Germany) was operated at $40 \mathrm{~mA} / 40 \mathrm{kV}$, with Ni-filtered $\mathrm{CuK} \alpha$ radiation and at the scan rate of $2.4^{\circ}(2 \theta) / \mathrm{min}$ with an interval of $0.04^{\circ}$. The following International Centre for Diffraction Data (ICDD) cards were used to identify the corresponding phases: $\mathrm{MoB}$ (51-0940), $\mathrm{Al}_{2} \mathrm{O}_{3}$ (46-1212), $\mathrm{Al}$ (65-2869), MoAlB (65-2497), $\mathrm{Al}_{5} \mathrm{Mo}$ (44-1102), $\mathrm{Al}_{4} \mathrm{Mo}$ (65-7072) and $\mathrm{Al}_{8} \mathrm{Mo}_{3}$ (65-1231). The microstructures and morphologies of the samples were characterised using a scanning electron microscope (SEM Nova Nanolab 600, FEI Company, Hillsboro, OR)) along with a JEM 2100 transmission electron microscope (TEM).

\section{Results}

\subsection{Effect of Firing Temperature on MoAlB Formation}

Figure 1 gives the XRD results of the samples with the stoichiometric composition after $6 \mathrm{~h}$ at $850-950{ }^{\circ} \mathrm{C}$. At $850{ }^{\circ} \mathrm{C}, \mathrm{Al}_{8} \mathrm{Mo}_{3}$ and $\mathrm{MoB}$ were formed as the primary phases, along with minor intermediate $\mathrm{AlMo}_{3}$ and impurity $\mathrm{Al}_{2} \mathrm{O}_{3}$ (the latter was likely resultant from the minor oxidation of $\mathrm{Al}$ by the impurity of $\mathrm{O}_{2}$ in the Ar gas), but no MoAlB was detected (Figure 1a). Upon increasing the temperature to $900{ }^{\circ} \mathrm{C}$, the same phases were detected, and their contents increased evidently, in particular, in the case of $\mathrm{AlMo}_{3}$. However, MoAlB was still not detectable by XRD (Figure 1b). Upon further increasing the temperature to $950{ }^{\circ} \mathrm{C}, \mathrm{AlMo}_{3}$ disappeared and MoAlB started to appear. $\mathrm{Mo}_{8} \mathrm{Al}_{3}$ and $\mathrm{MoB}$ were also formed, and the content of the latter became slightly higher than at $900{ }^{\circ} \mathrm{C}$ (Figure 1c). As a result of the formation of intermediate Mo-Al phases, most of the Al had been consumed. Consequently, only small amounts of free Al were available for MoAlB formation, which explained the limited formation of MoAlB at this temperature (Figure 1c). 


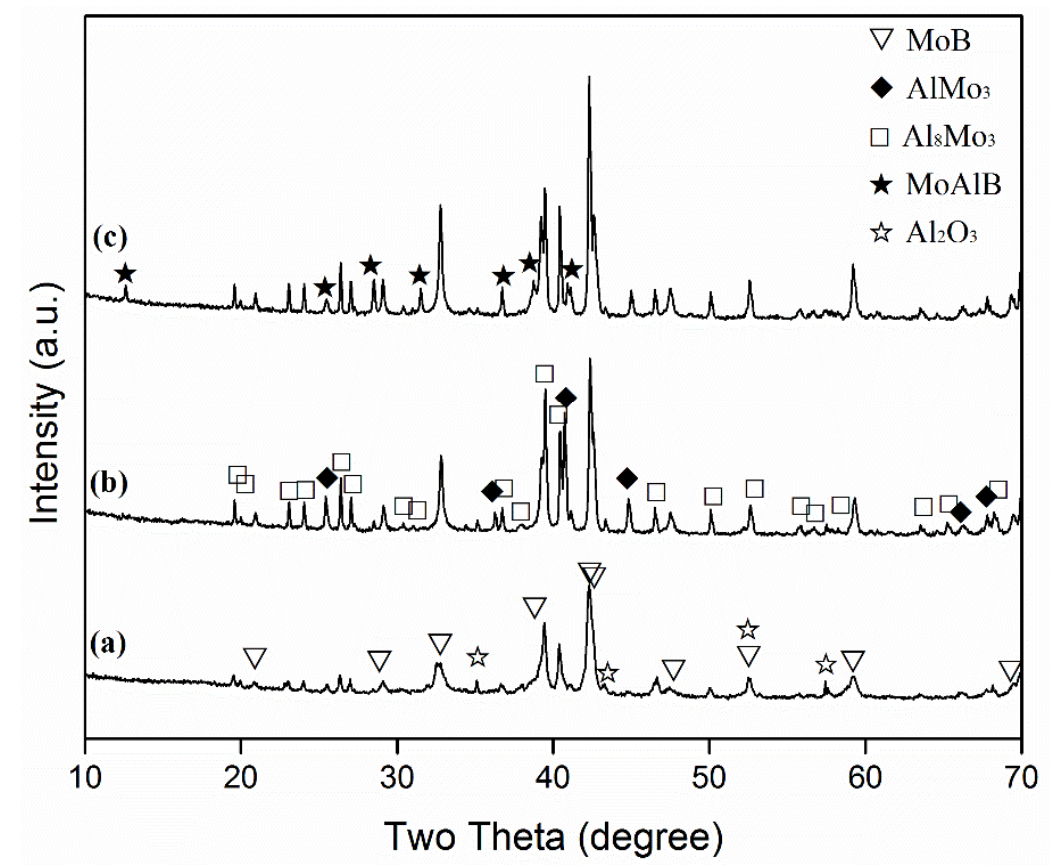

Figure 1. XRD spectra of the samples with the stoichiometric composition after $6 \mathrm{~h}$ at (a) 850, (b) 900 and $(\mathbf{c}) 950{ }^{\circ} \mathrm{C}$.

\subsection{Effect of Amount of Excess Al on MoAlB Formation}

Figure 2 illustrates the effect of excess $\mathrm{Al}$ on the phase formation and reaction extent in the samples after $6 \mathrm{~h}$ of firing at $850^{\circ} \mathrm{C}$. When the stoichiometric amount of $\mathrm{Al}$ was used (Figure 2a, i.e., Figure 1a), as already stated above, no MoAlB was detected, and $\mathrm{Al}_{8} \mathrm{Mo}_{3}$ and $\mathrm{MoB}$ were formed as the primary phases, along with minor impurity $\mathrm{Al}_{2} \mathrm{O}_{3}$. Upon increasing the excess $\mathrm{Al}$ to $60 \% \sim 80 \%$, the formation of MoAlB became evident, but $\mathrm{MoB}$ and $\mathrm{Al}_{8} \mathrm{Mo}_{3}$ still remained as the main phases (Figure $2 \mathrm{~b}, \mathrm{c}$ ). Upon further increasing the excess $\mathrm{Al}$ to $100-120 \%$, MoAlB further increased, whereas $\mathrm{MoB}$ and $\mathrm{Al}_{8} \mathrm{Mo}_{3}$ generally decreased. In addition, minor $\mathrm{Al}_{5} \mathrm{Mo}$ was detected (Figure $2 \mathrm{~d}, \mathrm{e}$ ). The above results indicated that increasing the excess Al generally favoured MoAlB formation, but inhibited the formation of intermediate phases. The intermediate phases detected were mainly in the Al-Mo binary phases along with minor $\mathrm{MoB}$, indicating that there should be some unreacted $\mathrm{B}$ (although not detectable by XRD because of its amorphous nature) remaining in all of the samples. The formation of Al-Mo phases in all of the samples indicated that they were stable in the presence of $\mathrm{B}$ at $850{ }^{\circ} \mathrm{C}$. Therefore, a higher synthesis temperature had to be used to avoid their formation and to complete the MoAlB formation reaction.

\subsection{Combined Effects of Excess Al and Firing Temperature on MoAlB Formation, and Optimisation of Synthesis Condition}

To illustrate the combined effects of excess $\mathrm{Al}$ and the firing temperature on the phase formation and reaction extent, and to further optimise the synthesis condition, samples with various amounts of excess Al were fired at different temperatures. Figure 3, for example, shows the XRD patterns of samples with $100-140 \%$ excess $\mathrm{Al}$ after $6 \mathrm{~h}$ of firing at 900 and $950{ }^{\circ} \mathrm{C}$, respectively, revealing similar phase formations in both cases, although slightly more MoAlB and less intermediate phases were formed at 950 than at $900{ }^{\circ} \mathrm{C}$. When $100 \%$ excess $\mathrm{Al}$ was used, $\mathrm{Al}_{8} \mathrm{Mo}_{3}$ and $\mathrm{MoB}$ were the main intermediate $\mathrm{Mo}-\mathrm{Al}$ phases. However, with increasing the excess $\mathrm{Al}$, these two phases decreased, but an Al-rich Al-Mo phase, $\mathrm{Al}_{5} \mathrm{Mo}$, was detected. The above results revealed that out of all of the samples, the one with $140 \%$ excess $\mathrm{Al}$ had the highest MoAlB formation and the least formation of intermediate $\mathrm{Al}-\mathrm{Mo}$ phases at $950^{\circ} \mathrm{C}$, further indicating that increasing the excess $\mathrm{Al}$ along with firing temperature had a synergistic effect on MoAlB formation. So, to make even purer MoAlB, samples 
with $120 \%$ and $140 \%$ excess $\mathrm{Al}$ were further fired at $1000{ }^{\circ} \mathrm{C}$ for $6 \mathrm{~h}$. As seen from Figure 4 , when $120 \%$ excess $\mathrm{Al}$ was used, apart from the primary phase of $\mathrm{MoAlB}$, only minor $\mathrm{Al}_{8} \mathrm{Mo}_{3}$ and residual $\mathrm{Al}$ were detected. However, upon increasing the excess Al to $140 \%$, all of the intermediate Al-Mo phases disappeared, and nearly phase pure MoAlB, along with minor residual $\mathrm{Al}$ and minor $\mathrm{Al}_{2} \mathrm{O}_{3}$, was formed. After leaching out the minor residual $\mathrm{Al}$ and $\mathrm{Al}_{2} \mathrm{O}_{3}$ with $\mathrm{HCl}$, phase pure MoAlB was finally obtained (Figure 5a). The elimination of $\mathrm{Al}$ was evidenced by the absence of its diffraction peaks, e.g., the strongest one at about $38.5^{\circ}(2 \theta)$ (Figure $5 \mathrm{~b}$ ). The synthesis temperature used here was at least $100{ }^{\circ} \mathrm{C}$ lower than that required by other synthesis routes reported previously $[1,3,8-13]$.

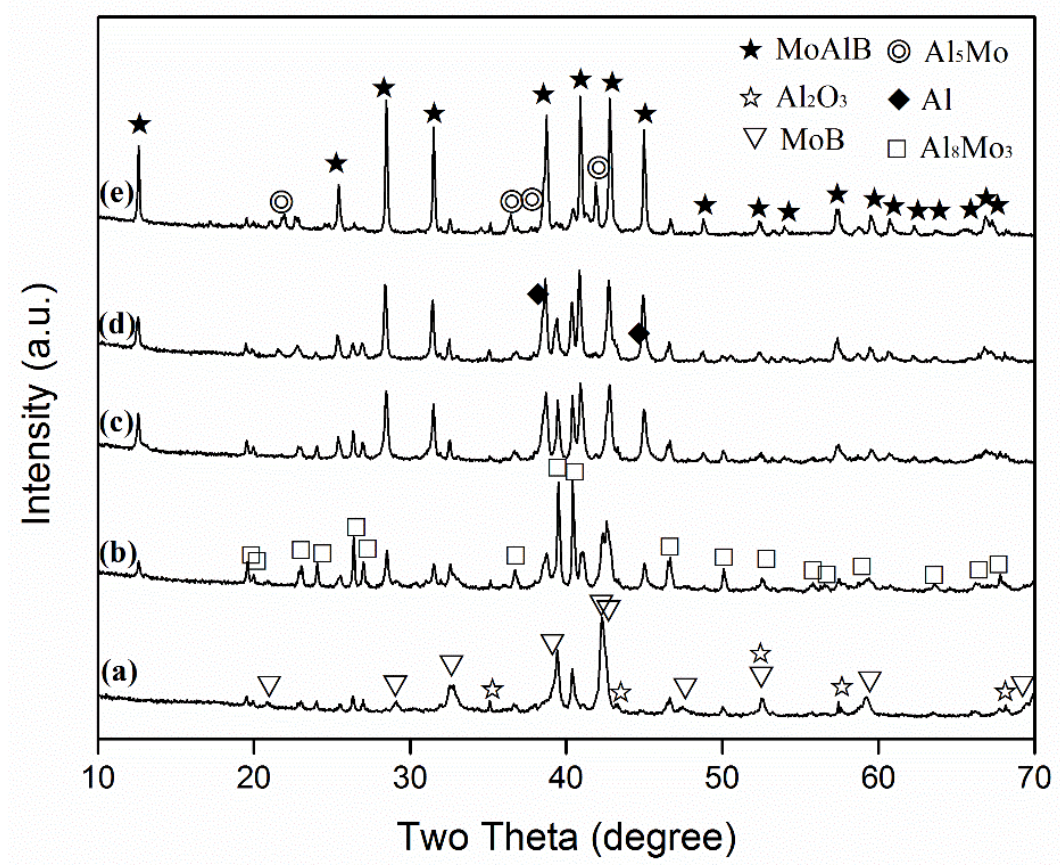

Figure 2. XRD spectra of the samples heated at $850{ }^{\circ} \mathrm{C}$ for $6 \mathrm{~h}$, with different amounts of excess $\mathrm{Al}$ at (a) stoichiometric amount, (b) $60 \%$, (c) $80 \%$, (d) $100 \%$ and (e) $120 \%$.

\subsection{Microstructural Characterisation of MoAlB Product Powder}

Figure 6 shows the SEM images of the MoAlB product powder resultant from $6 \mathrm{~h}$ of firing at $1000{ }^{\circ} \mathrm{C}$ and the subsequent purification with $\mathrm{HCl}$, revealing three different morphologies of the particles, namely: small rounded grains of 1 3 $\mu \mathrm{m}$ (highlighted by " $\mathrm{I}$ " in Figure 6), platelet-like (disc-like) particles of $<5 \mu \mathrm{m}$ in diameter (highlighted by "II" in Figure 6) and columnar crystals up to $20 \mu \mathrm{m}$ in length and up to $5 \mu \mathrm{m}$ in diameter (highlighted by "III" in Figure 6). These three forms of particles looked similar to those prepared by Shi et al. via the conventional mixed powder route using $\mathrm{Al}$ and $\mathrm{MoB}$ as the raw materials [15]. Some small pits were seen on the surfaces of the third form, which were similar to those reported by Kota and Shi et al. $[9,15]$, although the reason behind their formations was not clear.

Figure 7a further presents a TEM image of a representative MoAlB particle from the sample whose microstructure is shown in Figure 6. As a result of its micron-scale thickness, its lattice structure could not be revealed under TEM. Nevertheless, the selected area electron diffraction (SAED) pattern of the particle was obtained (Figure 7b). It was similar to that reported by Alameda et al. [16], confirming that the particle was an MoAlB crystal, which is believed to be as a result of the preferential growth in the [010] direction. 

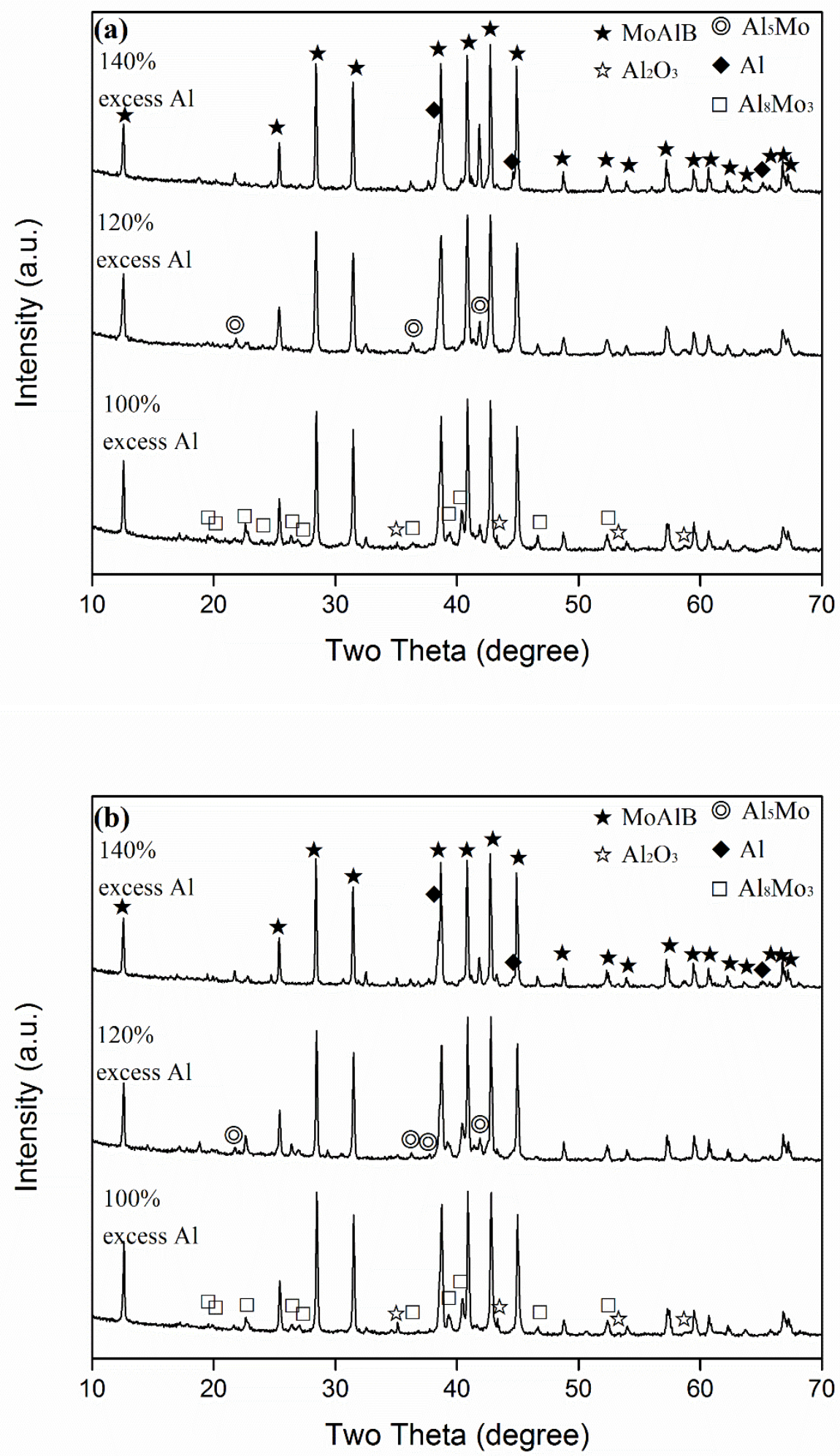

Figure 3. XRD patterns of the samples with various amounts of excess $\mathrm{Al}$, after $6 \mathrm{~h}$ of firing at (a) 900 and (b) $950{ }^{\circ} \mathrm{C}$, separately. 


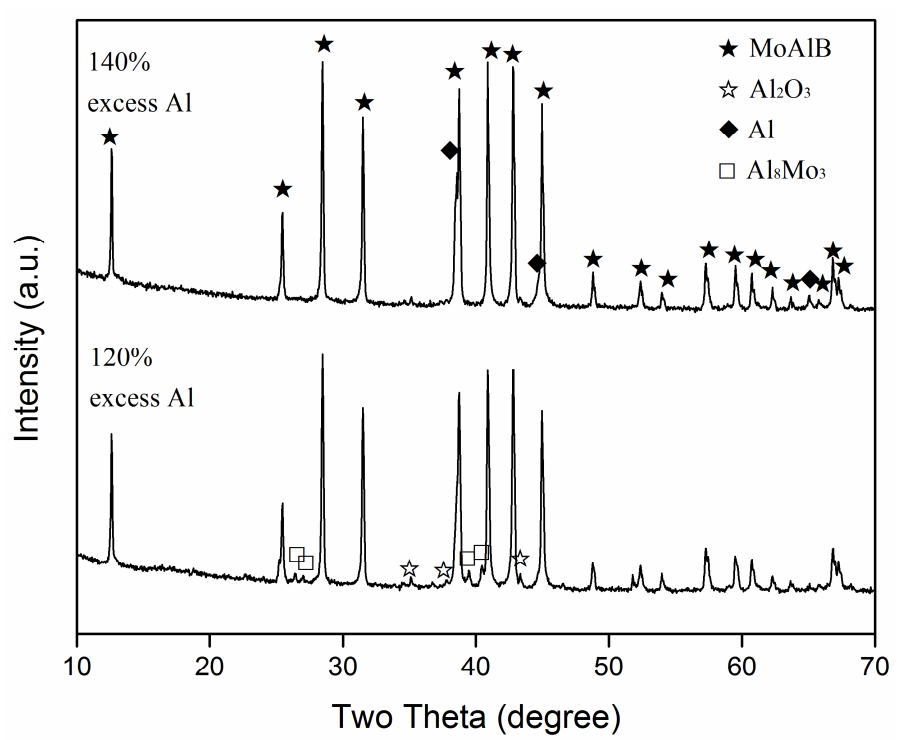

Figure 4. XRD patterns of samples with $120 \%$ and $140 \%$ excess $\mathrm{Al}$, separately, after $6 \mathrm{~h}$ of firing at $1000{ }^{\circ} \mathrm{C}$
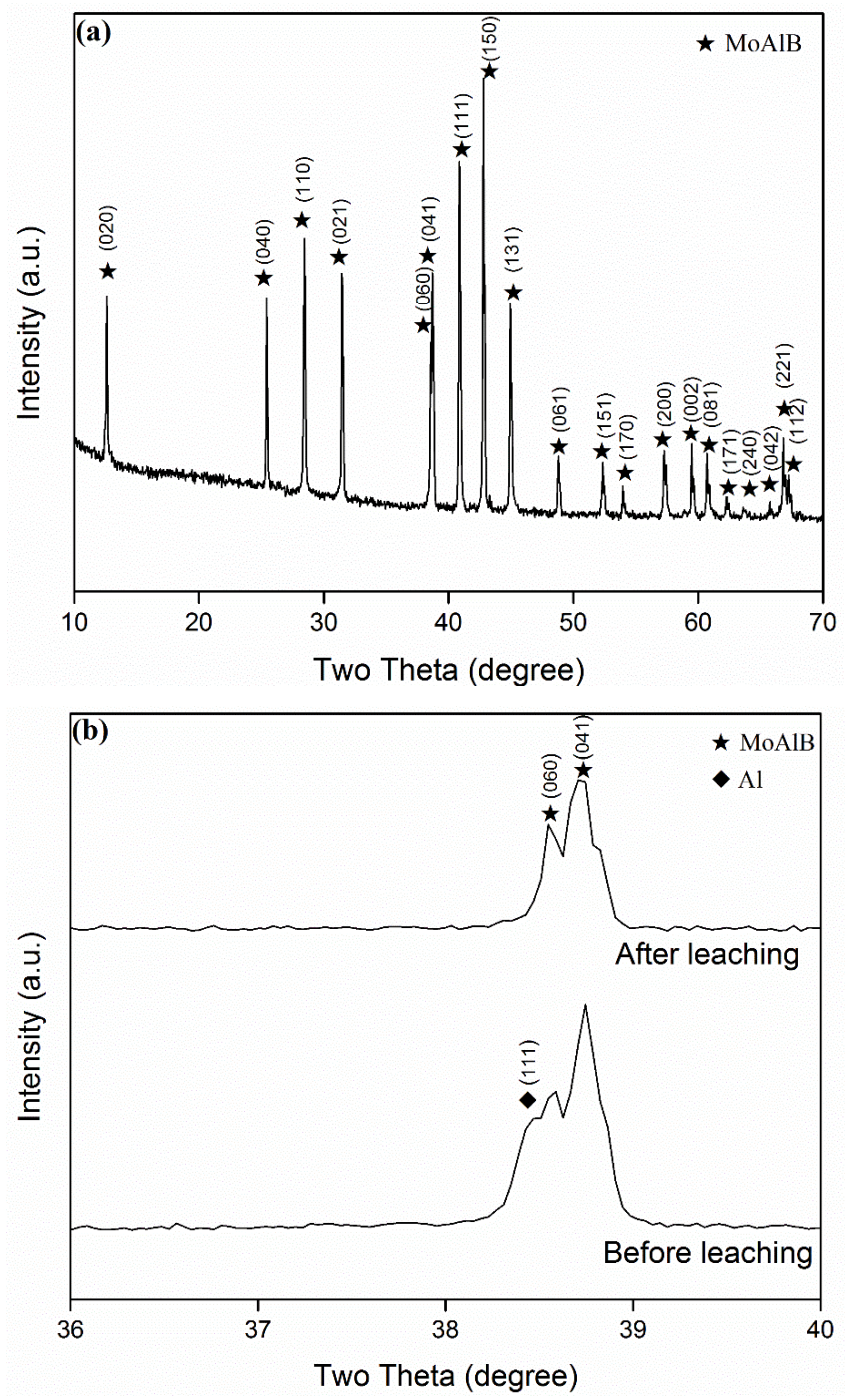

Figure 5. (a) XRD pattern of the sample after $6 \mathrm{~h}$ of firing at $1000{ }^{\circ} \mathrm{C}$ and the subsequent acid leaching, and (b) comparison of XRD patterns (within $36-40^{\circ}$ ) of the samples before and after acid leaching. 
(a)

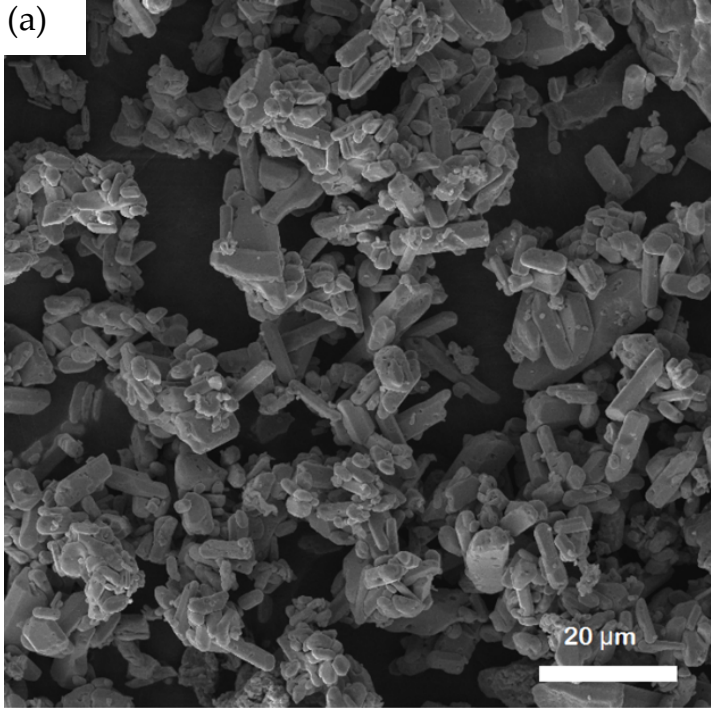

(b)

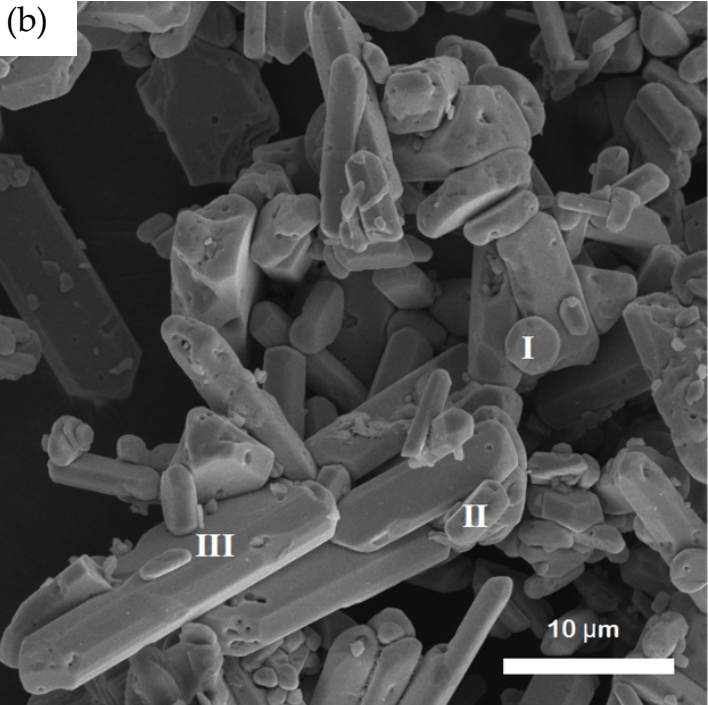

Figure 6. (a) Low and (b) high magnification SEM images of MoAlB particles resulting from $6 \mathrm{~h}$ of firing at $1000{ }^{\circ} \mathrm{C}$ and the subsequent acid leaching.

(a)

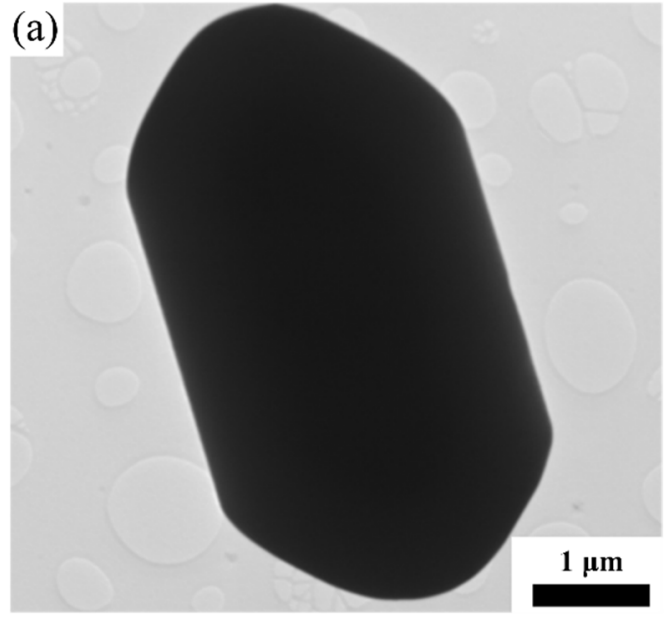

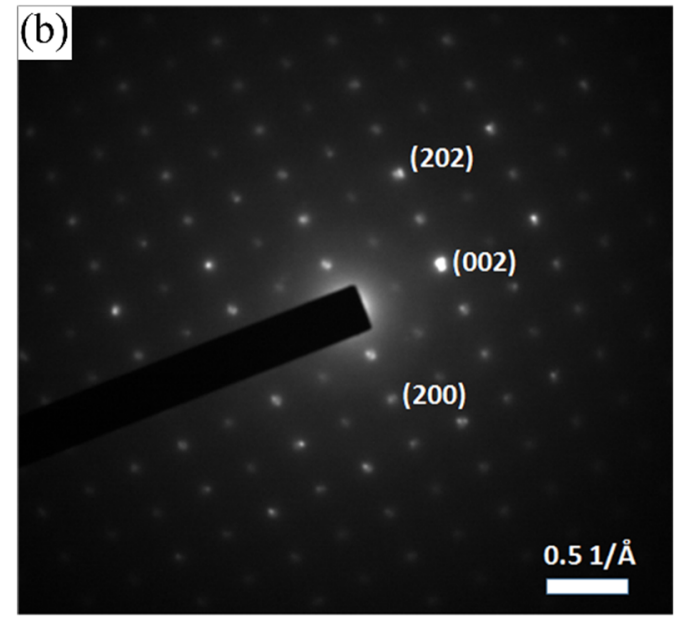

Figure 7. (a) TEM image and (b) selected area electron diffraction (SAED) of a representative MoAlB crystal in the sample, whose microstructure is shown in Figure 6.

\section{Discussion}

At the test temperatures, the $\mathrm{NaCl}$ (melting point $\sim 714^{\circ} \mathrm{C}$ ) melted, forming a homogeneous molten salt medium in which the $\mathrm{Al}$ (melting point $660.3^{\circ} \mathrm{C}$ ) melted, forming corresponding droplets. Although the exact solubility data of the $\mathrm{Al}$, $\mathrm{Mo}$ and $\mathrm{B}$ in the $\mathrm{NaCl}$ molten salt are not available, based on the previous studies on the molten salt synthesis of $\mathrm{Mo}_{2} \mathrm{C}$ [17], borides [18-20] and $\mathrm{TiB}_{2}-\mathrm{Al}_{2} \mathrm{O}_{3}$ [21], it can be considered that the solubility values should be in the following order: $\mathrm{Mo}>\mathrm{Al}>\mathrm{B}$. At a relatively low firing temperature $\left(850{ }^{\circ} \mathrm{C}\right)$, Mo was partially dissolved in the liquid salt, diffused quickly through it onto the $\mathrm{Al}$ droplets (or met with dissolved $\mathrm{Al}$ ) and $\mathrm{B}$ particles and then reacted to form intermediate phases $\mathrm{Al}_{8} \mathrm{Mo}_{3}$ and $\mathrm{MoB}$ according to Reactions (2) and (3), respectively (Figures 1a and 2a).

$$
\begin{aligned}
8 \mathrm{Al}+3 \mathrm{Mo} & =\mathrm{Al}_{8} \mathrm{Mo}_{3}\left(\Delta \mathrm{G}^{\circ}=-278.7 \mathrm{KJ} \text { at } 1000{ }^{\circ} \mathrm{C}\right) \\
\mathrm{Mo}+\mathrm{B} & =\operatorname{MoB}\left(\Delta \mathrm{G}^{\circ}=-110.4 \mathrm{KJ} \text { at } 1000{ }^{\circ} \mathrm{C}\right)
\end{aligned}
$$

No intermediate $\mathrm{Al}-\mathrm{B}$ phases (such as $\mathrm{AlB}_{2}$ ) were detected by $\mathrm{XRD}$ at this temperature (Figures $1 \mathrm{a}$ and $2 \mathrm{a}$ ). The reason might be that most of the $\mathrm{Al}$ had been consumed by the reaction with Mo, so almost 
no $\mathrm{Al}$ was left for its reaction with $\mathrm{B}$. Because of this and the limited solubility of $\mathrm{B}$ in the molten salt at this relatively low temperature, once $\mathrm{Al}_{8} \mathrm{Mo}_{3}$ and $\mathrm{MoB}$ were formed, it would be difficult for them to be converted into MoAlB via reacting with B and Al, respectively, i.e., Reactions (4) and (5) would not occur at this low temperature. This explained the absence of MoAlB in the sample with the stoichiometric amount of $\mathrm{Al}$ after firing at $850{ }^{\circ} \mathrm{C}$ (Figures $1 \mathrm{a}$ and $2 \mathrm{a}$ ).

$$
\begin{gathered}
\mathrm{Al}_{8} \mathrm{Mo}_{3}+3 \mathrm{~B}=3 \mathrm{MoAlB}+5 \mathrm{Al} \\
\mathrm{MoB}+\mathrm{Al}=\mathrm{MoAlB}
\end{gathered}
$$

With increasing the amount of excess $\mathrm{Al}$, MoAlB increased, whereas MoB decreased, indicating the occurrence of Reaction (5) and its gradually enhanced extent (Figure 2). Apart from this, some of the excess $\mathrm{Al}$ would react with the $\mathrm{Al}_{8} \mathrm{Mo}_{3}$ formed earlier, forming Al-rich $\mathrm{Al}-\mathrm{Mo}$ phases $\left(\mathrm{Al}_{\mathrm{x}} \mathrm{Mo}\right)$, as suggested by the Al-Mo phase diagram [22] and evidenced by the detection of $\mathrm{Al}_{5} \mathrm{Mo}$ (Figure 3). $\mathrm{Al}_{5} \mathrm{Mo}$ was not stable at the test temperatures, so it was believed to be formed upon cooling from the liquid with the same composition. This was responsible for the increased $\mathrm{Al}_{5} \mathrm{Mo}$ and decreased $\mathrm{Al}_{8} \mathrm{Mo}_{3}$ upon using more excess $\mathrm{Al}$ (Figures 2 and 3).

$$
\begin{gathered}
\mathrm{Al}_{8} \mathrm{Mo}_{3}+7 \mathrm{Al}=3 \mathrm{Al}_{5} \mathrm{Mo}\left(\Delta \mathrm{G}^{\circ}=-23.5 \mathrm{KJ} \text { at } 1000{ }^{\circ} \mathrm{C}\right) \\
\mathrm{Al}_{\mathrm{x}} \mathrm{Mo}+\mathrm{B}=\mathrm{MoAlB}+(\mathrm{x}-1) \mathrm{Al}
\end{gathered}
$$

In addition to the amount of excess $\mathrm{Al}$, the firing temperature significantly affected MoAlB formation, in cases both using and without using excess Al (Figures 1, 3 and 4). With increasing the firing temperature, the solubility of B in the molten salt would be increased. So, dissolved B would diffuse through the molten salt onto the remaining $\mathrm{Al}-\mathrm{Mo}$ phases $\left(\mathrm{Al}_{8} \mathrm{Mo}_{3}\right.$ and $\left.\mathrm{Al}_{\mathrm{x}} \mathrm{Mo}\right)$, and reacted with them to form MoAlB, according to Reactions (4) and (7) (Figures 1c, 3 and 4).

Based on the above discussion, it can be considered that phase pure MoAlB could only be prepared by using appropriate amounts of excess $\mathrm{Al}$ and firing at an appropriate temperature (in the present work, $140 \%$ excess $\mathrm{Al}$ at $1000{ }^{\circ} \mathrm{C}$ ). It is believed that the multiple-step reactions, in particular, the three different formation reactions (Reactions (4), (5) and (7)), were responsible for the different shapes and sizes of the MoAlB product particles (Figures 6 and 7), although future work is still needed to classify this further.

\section{Conclusions}

MoAlB fine particles were synthesised in molten $\mathrm{NaCl}$ at a lowered temperature, from $\mathrm{Al}, \mathrm{B}$ and Mo powders. The main conclusions are drawn as follows.

(1) MoAlB product particles exhibited three different shapes/sizes, namely: rounded particles $(1 \sim 3 \mu \mathrm{m})$, platelet-like particles $(<5 \mu \mathrm{m}$ in diameter) and columnar crystals with various lengths (up to $20 \mu \mathrm{m}$ ) and diameters (up to $5 \mu \mathrm{m}$ ), which are believed to be formed from different reaction processes.

(2) To prepare phase pure MoAlB, an appropriate amount of excess Al needs to be used and an appropriate firing temperature is required. In the present work, the optimal synthesis conditions were as follows: use of $140 \%$ excess $\mathrm{Al}$ and $6 \mathrm{~h}$ of firing at $1000^{\circ} \mathrm{C}$. This synthesis temperature was at least $100{ }^{\circ} \mathrm{C}$ lower than that required by the synthesis techniques reported previously.

(3) At the test temperatures, the $\mathrm{NaCl}$ and $\mathrm{Al}$ melted, forming a liquid pool and corresponding droplets, respectively. If the temperature was low (at $850^{\circ} \mathrm{C}$ ), Mo and $\mathrm{Al}$ partially dissolved in the liquid salt, but B did not dissolve. In this case, the dissolved Mo reacted with $\mathrm{Al}$ (dissolved and/or undissolved) and undissolved $\mathrm{B}$, forming intermediate $\mathrm{Al}_{8} \mathrm{Mo}_{3}$ and $\mathrm{MoB}$, respectively. When excess $\mathrm{Al}$ was used, it was partially dissolved in the salt and diffused onto the surfaces of $\mathrm{MoB}$ and $\mathrm{Al}_{8} \mathrm{Mo}_{3}$, and reacted to form MoAlB and Al-rich $\mathrm{Al}-\mathrm{Mo}$ phases $\left(\mathrm{Al}_{\mathrm{x}} \mathrm{Mo}\right)$, respectively. With increasing the temperature to $>900{ }^{\circ} \mathrm{C}$, the dissolution of $\mathrm{B}$ in the salt became more significant. So, the dissolved $\mathrm{B}$ 
would diffuse through the molten salt onto the surfaces of the intermediate Al-Mo phases formed earlier, and reacted with them to form additional MoAlB.

Author Contributions: Experiment and initial draft, C.L.; conception and experiment design, C.L., X.L. and Z.H.; review and editing, S.Z., Q.J. and X.L., supervision: S.Z. All authors have read and agreed to the published version of the manuscript.

Funding: This research was partially funded by the Royal Society, grant number IF140067.

Conflicts of Interest: The authors declare no conflict of interest.

\section{References}

1. Alameda, L.T.; Moradifar, P.; Metzger, Z.; Alem, N.; Schaak, R.E. Topochemical Deintercalation of Al from MoAlB: Stepwise Etching Pathway, Layered Intergrowth Structures, and Two-Dimensional MBene. J. Am. Chem. Soc. 2018, 140, 8833-8840. [CrossRef]

2. Ali, M.A.; Hadi, M.A.; Hossain, M.M.; Naqib, S.H.; Islam, A.K.M.A. Theoretical investigation of structural, elastic, and electronic properties of ternary boride MoAlB. Phys. Status Solidi B. 2017, 254, 1700010. [CrossRef]

3. Kota, S.; Zapata-Solvas, E.; Ly, A.; Lu, J.; Elkassabany, O.; Huon, A.; Lee, W.E.; Hultman, L.; May, S.J.; Barsoum, M.W. Synthesis and characterization of an alumina forming nanolaminated boride: MoAlB. Sci. Rep. 2016, 6, 26475. [CrossRef] [PubMed]

4. Li, X.; Cui, H.; Zhang, R. First-principles study of the electronic and optical properties of a new metallic MoAlB. Sci. Rep. 2016, 6, 39790. [CrossRef] [PubMed]

5. Lu, X.; Li, S.; Zhang, W.; Yu, W.; Zhou, Y. Thermal shock behavior of a nanolaminated ternary boride: MoAlB. Ceram. Int. 2018, 45, 9386-9389. [CrossRef]

6. Xu, L.; Shi, O.; Liu, C.; Zhu, D.; Grasso, S.; Hu, C. Synthesis, microstructure and properties of MoAlB ceramics. Ceram. Int. 2018, 44, 13396-13401. [CrossRef]

7. Bai, Y.; Qi, X.; Duff, A.; Li, N.; Kong, F.; He, X.; Wang, R.; Lee, W.E. Density functional theory insights into ternary layered boride MoAlB. Acta Mater. 2017, 132, 69-81. [CrossRef]

8. Kota, S.; Agne, M.; Zapata-Solvas, E.; Dezellus, O.; Lopez, D.; Gardiola, B.; Radovic, M.; Barsoum, M.W. Elastic properties, thermal stability, and thermodynamic parameters of MoAlB. Phys. Rev. B 2017, 95, 144108. [CrossRef]

9. Kota, S.; Zapata-Solvas, E.; Chen, Y.; Radovic, M.; Lee, W.E.; Barsoum, M.W. Isothermal and Cyclic Oxidation of MoAlB in Air from $1100{ }^{\circ} \mathrm{C}$ to $1400{ }^{\circ} \mathrm{C}$. J. Electrochem. Soc. 2017, 164, C930-C938. [CrossRef]

10. Okada, S. Synthesis, crystal structure and characterizations of the ternary borides TMAlB (TM= Mo, W) with UBC type structure. Sci. Rep. 1998, 31, 7-12.

11. Ade, M.; Hillebrecht, $\mathrm{H}$. Ternary borides $\mathrm{Cr}_{2} \mathrm{AlB}_{2}, \mathrm{Cr}_{3} \mathrm{AlB}_{4}$, and $\mathrm{Cr}_{4} \mathrm{AlB}_{6}$ : The first members of the series $\left(\mathrm{CrB}_{2}\right)_{\mathrm{n}} \mathrm{CrAl}$ with $\mathrm{n}=1,2,3$ and a unifying concept for ternary borides as MAB-phases. Inorg. Chem. 2015, 54, 6122-6135. [CrossRef] [PubMed]

12. Kanatzidis, M.G.; Pöttgen, R.; Jeitschko, W. The metal flux: A preparative tool for the exploration of intermetallic compounds. Angew. Chem. Int. Edit. 2005, 44, 6996-7023. [CrossRef]

13. Lou, T. Microstructure and Properties of Spark Plasma Sintered MoAlB Ceramics. Ph.D. Thesis, University of Nebraska-Lincoln, Lincoln, CA, USA, 2016.

14. Fuka, M.R. Synthesis and Characterization of Novel Ternary Borides (MoAlB) and Their Composites. Ph.D. Thesis, The University of North Dakota, Grand Forks, ND, USA, 2018.

15. Shi, O.; Xu, L.; Jiang, A.; Xu, Q.; Xiao, Y.; Zhu, D.; Grasso, S.; Hu, C. Synthesis and oxidation resistance of MoAlB single crystals. Ceram. Int. 2019, 45, 2446-2450. [CrossRef]

16. Alameda, L.T.; Holder, C.F.; Fenton, J.L.; Schaak, R.E. Partial etching of Al from MoAlB single crystals to expose catalytically active basal planes for the hydrogen evolution reaction. Chem. Mater. 2017, 29, 8953-8957. [CrossRef]

17. Yang, R.; Cui, L.; Zheng, Y.; Cai, X. Molten salt synthesis of $\mathrm{Mo}_{2} \mathrm{C}$ powder using a mechanically milled powder. Mater. Lett. 2007, 61, 4815-4817. [CrossRef]

18. Bao, K.; Wen, Y.; Khangkhamano, M.; Zhang, S. Low-temperature preparation of titanium diboride fine powder via magnesiothermic reduction in molten salt. J. Am. Ceram. Soc. 2017, 100, 2266-2272. [CrossRef] 
19. Bao, K.; Massey, J.; Huang, J.; Zhang, S. Low-temperature synthesis of hafnium diboride powder via magnesiothermic reduction in molten salt. Adv. Ceram. Compos. 2017, 38, 119.

20. Bao, K.; Lin, L.; Chang, H.; Zhang, S. Low-temperature synthesis of calcium hexaboride nanoparticles via magnesiothermic reduction in molten salt. J. Ceram. Soc. JPN. 2017, 125, 866-871. [CrossRef]

21. Bao, K. Low Temperature Synthesis of Boron-Based Materials in Molten Salts. Ph.D. Thesis, University of Exeter, Exeter, UK, 2017.

22. Brewer, L.; Lamoreaux, R.H.; Ferro, R.; Marazza, R. The Al-Mo system (Aluminum-Molybdenum). Bull. Alloy Phase Diagr. 1980, 1, 71-75. [CrossRef]

(C) 2020 by the authors. Licensee MDPI, Basel, Switzerland. This article is an open access article distributed under the terms and conditions of the Creative Commons Attribution (CC BY) license (http://creativecommons.org/licenses/by/4.0/). 